\title{
Erratum to: Direct healthcare costs for 5 years post-fracture in Canada
}

\section{A long-term population-based assessment}

W. D. Leslie • L. M. Lix • G. S. Finlayson • C. J. Metge •

S. N. Morin • S. R. Majumdar

Published online: 11 September 2013

(C) International Osteoporosis Foundation and National Osteoporosis Foundation 2013

Erratum to: Osteoporos Int (2013) 24:1697-1705

DOI 10.1007/s00198-012-2232-2

The Supplementary Online Table 1 (Incremental mean costs up to 5 years following non-traumatic fracture) was omitted from the original publication due to an oversight.

The online version of the original article can be found at http://dx.doi.org/ 10.1007/s00198-012-2232-2.

W. D. Leslie $(\bowtie)$

Department of Medicine (C5121), University of Manitoba, 409

Tache Avenue, Winnipeg, MB R2H 2A6, Canada

e-mail: bleslie@sbgh.mb.ca

L. M. Lix · G. S. Finlayson · C. J. Metge

University of Manitoba, 409 Tache Avenue, Winnipeg, Manitoba

R2H 2A6, Canada

S. N. Morin

McGill University, Montreal, Quebec, Canada

e-mail: suzanne.morin@mcgill.ca

S. R. Majumdar

University of Alberta, Edmonton, Alberta, Canada

e-mail:me2.majumdar@ualberta.ca 